\title{
Resource Scheduling and Strategic Management of Smart Cities under the Background of Digital Economy
}

\author{
Qing Yin $\mathbb{D}^{1,2}$ and Gang Liu ${ }^{1}$ \\ ${ }^{1}$ School of Business, East China University of Science and Technology, Xuhui, Shanghai 200237, China \\ ${ }^{2}$ Henan University of Animal Husbandry and Economy, Zhengzhou, Henan 450000, China \\ Correspondence should be addressed to Qing Yin; y10180446@mail.ecust.edu.cn
}

Received 3 October 2020; Revised 13 November 2020; Accepted 17 November 2020; Published 28 November 2020

Academic Editor: Zhihan Lv

Copyright ( 2020 Qing Yin and Gang Liu. This is an open access article distributed under the Creative Commons Attribution License, which permits unrestricted use, distribution, and reproduction in any medium, provided the original work is properly cited.

\begin{abstract}
Smart city is a brand-new city form, in which information and communication technologies are utilized to sense, analyze, and integrate the key information of city operation core system, so that intelligent responses can be immediately and effectively taken to various demands including people's livelihood, environmental protection, public safety, city services, and industrial and commercial activities. Digital economy is a mixed economy with the coexistence of multiple business models and diversified value creation models based on the information and communication technologies and in the digital economy, many things are undergoing huge changes, and their corresponding economic rules also need to be adjusted. On the basis of analyzing previous research works, this paper expounded the research status and significance of smart city's resource scheduling and strategic management, elaborated the development background, current status, and future challenges of digital economy, introduced the methods and principles of city-level spatiotemporal data model and spatial full factor coding, formulated resource scheduling strategies for smart city based on digital economy, explored the dynamic fusion, storage, and update of smart city's multisource heterogeneous data, conducted the information display and analysis of multilevel smart city, proposed strategic management approaches for smart city based on digital economy, analyzed the integrated implementation model of shared resource scheduling and people-oriented social management, and discussed the economic growth factors and standardization mechanism of smart city under the background of digital economy. The results of this study provide a reference for further research studies on the resource scheduling and strategic management of smart city under the background of digital economy.
\end{abstract}

\section{Introduction}

Smart city is a brand new city form which builds a smart and intelligent environment to support the city development; it utilizes cutting-edge information technology methods, such as the Internet of Things, cloud computing, optical networks, and mobile Internet, to integrate the scattered and fragmented information systems in a city into an organic whole with better synergy and regulation capabilities, so as to intelligently respond to various needs of public services, social management, industrial operations, and other activities [1]. The essence of a smart city is to make use of advanced information technology to realize smart management and operation of the city, thereby creating a better life for people in the city and promoting the harmonious and sustainable growth of the city [2]. The security of a smart city is a key indicator of its informationawareness layer. The analysis of city security characteristics is the basis for the construction of a smart city model, but this analysis model does not take into account factors such as the city environment, government services, and infrastructure. The construction of a new type of smart city includes four key elements of the open architecture of the Internet of Things, the city's open information platform, the city operation command center, and cyberspace security. The development of the concept of smart city and related applications can promote the realization of a consumptiondriven economic development mode from the three aspects of increasing household consumption, corporate consumption, and government consumption [3]. In addition, 
the information, the Internet of Things, and related industry development brought by the development of smart city can also promote industrial structure adjustment from the three aspects of coordinating the proportion of the three industries, improving industrial quality, and developing emerging industries and these three aspects reflect to varying degrees rationalization and advanced industrial structure [4].

Digital economy is a mixed economic system, in which information technology and computer technology are widely used. The use of information technology and computer technology has fundamentally changed the mode and situation of economic environment and economic activities [5]. The management system and multiple departments are indeed very important for the overall deployment and construction planning tasks of a smart city. In the digital economy, the transactions of management system usually have the characteristics of digitization, virtualization, concealment, and electronic payment in its multiple departments, which make it difficult to judge the consumption of trading venues and provide goods and services. In addition, the digital economy can provide better support for production, distribution, sales, and other goods and services, thereby creating a win-win environment for businesses and consumers [6]. The essence of the digital economy lies in informatization, which is a completely new social and political and economic system that fully digitizes information and business activities, including the development of information technology such as information technology, traditional industries, infrastructure, and social life [7]. The era of the digital economy is an era of globalized market competition, knowledge, and convergence and knowledge is spreading, accumulating, and updating more quickly due to the development of information technology and communication networks. The smart city is the main carrier of the development of the digital economy; digital economy is also the main feature of the development of the industrial economy of the smart city and the two are mutually reinforcing and mutually dependent relationships [8].

On the basis of analyzing previous research works, this paper expounded the research status and significance of smart city's resource scheduling and strategic management, elaborated the development background, current status, and future challenges of digital economy, introduced the methods and principles of city-level spatiotemporal data model and spatial full factor coding, formulated resource scheduling strategies for smart city based on digital economy, explored the dynamic fusion, storage, and update of smart city's multisource heterogeneous data, conducted the information display and analysis of multilevel smart city, proposed strategic management approaches for smart city based on digital economy, analyzed the integrated implementation model of shared resource scheduling and peopleoriented social management, and discussed the economic growth factors and standardization mechanism of smart city under the background of digital economy. The detailed section arrangement is as follows: Section 2 introduces the methods and principles of city-level spatiotemporal data model and spatial full factor coding; Section 3 formulates resource scheduling strategies for smart city based on digital economy; Section 4 proposes the strategic management approaches for smart city based on digital economy; Section 5 discusses the economic growth factors and standardization mechanism of smart city; Section 6 is conclusion.

\section{Methods and Principles}

2.1. City-Level Comprehensive Spatiotemporal Data Model. Due to the different dimensions of the indicators in the evaluation index system for digital economy development, the orders of magnitude differ greatly and they tend to increase [9]. Therefore, the initial data of the basic data is transformed into a comparable sequence and the calculation method is as follows:

$$
P_{i j}=\frac{X_{i j}}{Y_{i j}},
$$

where $P_{i j}$ is the data of the $i$-th index at the beginning of the $j$ th year; $X_{i j}$ is the original data; and $Y_{i j}$ is the value of the $i$-th index at the $j$-th year and the weight of each index is calculated as follows:

$$
S_{i j}=-k \cdot \sum_{i, j=1}^{n} p_{i j} \ln P_{i j}, i=1,2, \ldots, n,
$$

where $k$ is the fractal coefficient of the digital economy; $p_{i j}$ is the proportion of the value of the $i$-th index in the $j$-year value of the indicator; and $S_{i j}$ is the information entropy of the $i$-th index in the $j$-th year.

According to the characteristics and basic structure of smart city, the intelligent system of city public facilities based on digital economy is designed and the model of building smart buildings can be expressed as

$$
S_{a b}=\frac{\alpha\left(a_{1}-b_{2}\right)+\beta\left(a_{1}+b_{2}\right)}{S_{a}^{\beta} \cdot S_{b}^{\alpha}}+X_{a b} \cdot Y_{a b},
$$

where $a_{1}$ and $b_{2}$ are the factors of the digital economy system; $\alpha$ is the feature space factor of the smart city; $\beta$ is the dimension of the divergence matrix; $S_{a}^{\beta}$ and $S_{b}^{\alpha}$ are the interclass divergence matrix and intra-class divergence matrix, respectively; and $X_{a b}$ and $Y_{a b}$ are the city dimension spatial data sample set and feature attribute points, respectively.

Constraint equations that use the digital economy to optimize city-level spatiotemporal data are

$$
W\left(S_{i j}\right)=\left\{\begin{array}{cc}
w_{1}, & 0<S_{i j} \leq h_{1}, \\
w_{2}, & d_{1}<S_{i j} \leq h_{2}, \\
& \vdots \vdots \\
w_{k}, & h_{k-1}<S_{i j} \leq 1,
\end{array}\right.
$$

where $W\left(S_{i j}\right)$ is the constraint condition that the average dimension of the parameters of smart optimization system needs to meet; $w_{k}$ is the interference caused by the digital economy background to city construction problems; and $h_{k}$ is the global information feature vector of the smart city. So the city-level spatiotemporal comprehensive data model is calculated as 


$$
Q_{x}=P_{i j} \cdot W\left(S_{i j}\right)+\xi \cdot \frac{f\left(X_{i j}, Y_{i j}\right) \cdot S_{a b}}{\gamma \cdot\left(x_{i}+y_{j}\right)},
$$

where $Q_{x}$ is the equipment mark of the digital economy; $\xi$ is the correlation factor; $f\left(x_{i j}, x_{i j}\right)$ represents the regression basis function; $x_{i}$ is the principle of minimizing the intelligent use of digital resources; $y_{j}$ is the city optimization factor; and $\gamma$ is the minimum value of the constraint.

2.2. City-Level Spatial Full Factor Coding. The digital economy's impact on the current tax system is comprehensive, involving multiple aspects of the impact on the elements of the tax system itself, the division of tax jurisdiction, and the impact on the current tax collection and management system [10]. When the digital economy shows extremely complex shapes, it cannot be expressed by simple mathematical expressions, but only approximate mathematical functions can be used to approximate the actual situation. According to its coding requirements for city spatial elements, its fitting function $P\left(x_{i}, y_{i}, z_{i}\right)$ can be expressed as

$$
P\left(x_{i}, y_{i}, z_{i}\right)=\sum_{i=1}^{n} S_{i}\left(\frac{x_{i}^{2}}{Q_{x}^{2}} \cdot \ln \frac{y_{i}^{2}}{Q_{x}^{2}}+\frac{z_{i}^{2}}{Q_{x}^{2}}\right) .
$$

In the formula, $Q_{x}^{2}$ is the influence radius of discrete points; $Q_{x}^{2}=\left(x-x_{i}\right)^{2}+\left(y-y_{i}\right)^{2}+\left(z-z_{i}\right)^{2} ; x_{i}, y_{i}$, and $z_{i}$ $(i=1,2, \ldots, n)$ are the sampling data of discrete points on the digital system; and $S_{i}$ is the undetermined coefficient, given by the information of the known points.

The city-level spatial all-elements group is updated synchronously; that is, after $m$ elements complete their respective traversal searches, the digital information is updated and adjusted uniformly. If $k_{i j}(n)$ is assumed as the information factor after the nth cycle, the following formula can be obtained:

$$
k_{i j}(n)=(1-\lambda) k_{i j}(n-1)+\sum_{i, j=1}^{m} \Delta k_{i j}^{n}
$$

where $\lambda$ is the volatility coefficient of the total space factor, $(1-\lambda)$ is the digital information, and it is also the pheromone residual factor, and $\Delta k_{i j}^{n}$ is the digital increment of the $k$-th space full factor on the path in this cycle.

In order to calculate the coding time required for each spatial element of a smart city under different digital economic conditions, the execution matrix is defined as

$$
H(i, j)=\left[\begin{array}{cccc}
h_{11} & h_{12} & \cdots & h_{1 m} \\
h_{21} & h_{22} & \cdots & h_{2 m} \\
\vdots & \vdots & \vdots & \vdots \\
h_{n 1} & h_{n 1} & \cdots & h_{n m}
\end{array}\right]
$$

where $k_{i j}$ represents the encoding time required to represent the digital economic conditions $h_{i}$ to process the full space elements $h_{j}$. If $H(i, j)$ is assumed as the gradient value of the previous feature point, and $J(i, j)$ is the gradient value of the neighboring features centered on the current feature point, the gradient discrimination factor $R(i, j)$ can be defined as

$$
R(i, j)=\max || J(i, j)|-| H(i, j) \cdot J(i, j)|| .
$$

It can be known from the above formula that the gradient discrimination factor $R(i, j)$ is the minimum value of the difference between the gradient modulus value of the current element and the $n$ neighboring point modulus values in the digital economic model; then, the adaptive fractional order expression is defined as

$$
A(i, j)= \begin{cases}\frac{J(i, j)-H(i, j)}{\max [J(i, j)]-\nu \cdot R(i, j)}, & R(i, j) \geq K, \\ 0, & R(i, j)<K .\end{cases}
$$

In the formula, $v$ is the adjustment coefficient of spatial full-element coding; $\max [G(i, j)]$ is the maximum gradient of $n$ feature points; and $K$ is the threshold value selected according to different smart city models. When the required gradient value of the processed space and the gradient value of the surrounding elements change greatly, that is, when the gradient discrimination factor is greater than a given threshold value, it is considered that the encoding of the spatial full factor is successful.

\section{Resource Scheduling of Smart City Based on Digital Economy}

3.1. Dynamic Fusion, Storage, and Update of Multisource Heterogeneous Data. The spatial and temporal characteristics are the obvious characteristics of each element in the city. The information analysis of the smart city should straighten out the relationship between different elements, find similarities among them, and centrally process the information of all parties. The city-level spatiotemporal comprehensive data model can not only complete the establishment of a city-level spatiotemporal comprehensive data conceptual model from the perspectives of multiple dimensions, multiple temporalities, multiple dimensions, or even the four dimensions of multiple topics. The intangibility and mobility of the digital economy make the connection factors that determine tax jurisdiction disappear or become obscured, which brings challenges to the traditional standards for determining tax jurisdictions of residential places and source jurisdictions. In the application of comprehensive information, comprehensive analysis of multisource heterogeneous business, and integration sorting, processing and clarification of data are analyzed to determine the dwelling form of information collection and construction of judgment paths to provide multitopic information service. The framework of resource scheduling of smart city under the background of digital economy is shown in Figure 1. The information system design indeed needs to be continuously adjusted and updated as the environment changes. The digital economy mainly presents the economic process of manufacturing and supplying electronic products and services for commerce or trading activities caused by commerce. In this process, production and 


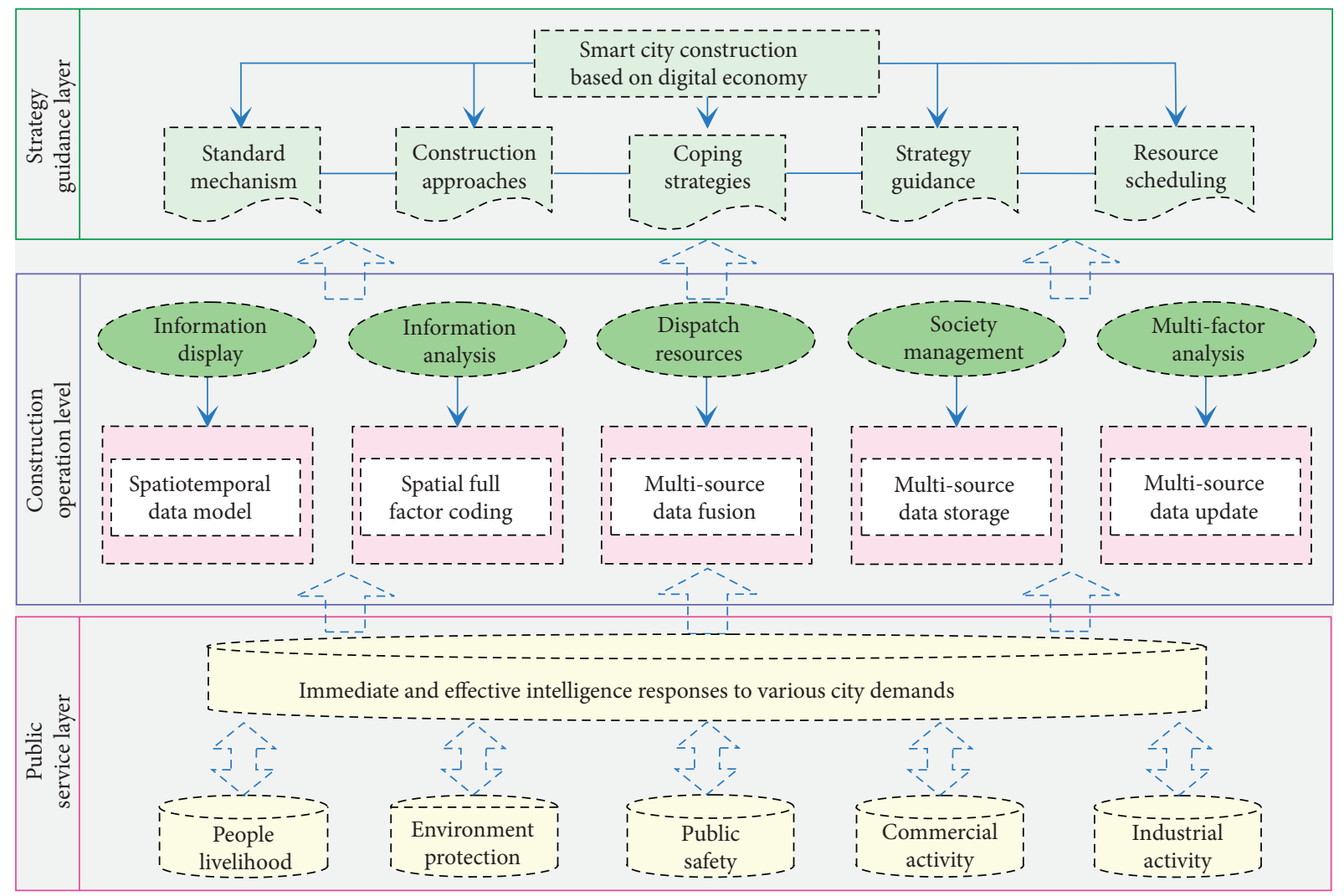

FIGURE 1: Framework of resource scheduling of smart city under the background of digital economy.

management are electronic as the environment changes, in which various suppliers and consumers and related activities are connected through the information analysis technology.

A smart city is of comprehensive structural design, technology integration, and three-dimensional services. Technical cooperation in the areas of city governance, city planning, industrial informatization, and architecture is required to achieve a high degree of integration, resource optimization, and highly interconnected technology and functions. At the same time, it is also a strategy for advancing smart city, which is different from the core of the previous informatization and digital cities. It also emphasizes the organic connectivity and functional realization of city households between different industries, internal industries, and other factors. Therefore, the coordination of the smart city industry has become a key path to accelerate the landing of the smart city industry. Most of the key projects in the areas of smart life, smart city management, and smart government affairs are invested and led by the government. The starting point is mainly from serving city management and administrative approval and there is a certain misalignment between project design, business services, and citizen demand. From supply to demand, the model is usually not timely, accurate, and comprehensive to meet the needs of citizens, and the government has not established an information-based active service mechanism for the needs of social entities. Smart city construction funds are mainly used in transportation, security, and other fields that have an important impact on city construction and management, not at the community level, which is closely related to people's livelihood; social capital investment has not formed an effective business model [11].

In order to complete the overall deployment and construction planning tasks of a smart city, the management system must be first improved and multiple departments should be involved in the implementation of the planning and design process. Therefore, a dedicated smart city department must be established to form the smart city's affairs and materials. The management mechanism of talents and people is followed by effective planning and top-level design of a smart city to effectively adapt to modern development, and then the construction of a city performance evaluation system, to effectively ensure the healthy development of the city [12]. In order to enhance the driving force of smart city planning and design, it must actively implement innovation, rely on the latest science and technology to achieve effective docking with smart city, and ensure the source of power for smart city planning and design. The technological innovation environment must be first optimized and the public integrated process of the service platform then should be improved to guide the whole society to actively innovate and start businesses. The smart home function can be added, and city residents can centrally control the homes at home and they can also understand the price and quality of different home products in a unified interface. At the same time, they can set up corresponding merchant connection services to ensure that merchants can integrate the latest home products and push residents to build a contact platform for merchants and residents. 
3.2. Multilevel City Comprehensive Information Display and Analysis. An information system cannot be successfully designed at one time, which is necessary to improve the design incompletely during operation and continuously adjust and update as the environment changes and the selfimproving ability is the core of the system's vitality. The long-acting system is not a static system, but an adaptive system with a self-regulating improvement mechanism, and the project management mechanism is the key point. Choosing an appropriate management model is a guarantee for the long-term benefits of the project and projects that do not fully consider the management model are not feasible. The selectable management mode of the city's intelligent system which includes government, cause and non-profit organization and enterprise. The different management modes and mechanisms have their own advantages and should be selected according to the characteristics of the service business [6]. The key to the sustainability of an information sharing system is to establish a quality assurance mechanism for data resource providers. Innovative ideas need to be reflected through project optimization, and planning attention should be focused on policy design and project selection. Table 1 shows the rating system of smart city resource scheduling based on digital economy. The smart city is not expected to bring shortcuts to information construction and information is only a tool for city development and the benefits of the tools need to be matched with the environment. The transformation and reconstruction of the environment must not be abrupt, and the smart city cannot bring sudden changes; mentality does not always want to leapfrog development and there are many benefits achieved by reducing the scale of the project.

The core of a smart city is a smarter way to change the way governments, communities, or companies and people interact with each other through a new generation of information technology to improve the clarity, efficiency, flexibility, and responsiveness of interactions with basic characteristics of perception, interconnection, and intelligence. From a technical perspective, the basic structure of a smart city mainly includes the Internet of Things, data center, city management, and operation levels, which correspond to the smart city intelligent sensing network, information resource center, operation management application layer, and public service center. Figure 2 shows the relationship between encoding relative time and index system rating in the resource scheduling and strategic management of smart city. The core technologies of smart city include intelligent identification, mobile computing, cloud computing, and information fusion and the public information services usually refer to the process of implementing open and developing services for public information. It includes two levels of open services and development services, including information on public affairs management activities, as well as information related to public interests, public policies, and arrangements and implementation of public management systems. Under the strategic guidance of the top-level design, starting from the core function of public information service push, the innovation of the value supply of the platform and the business model is achieved, driving the innovation of smart city form through the integration of multistakeholders.

The construction of a smart city is a complex and systematic project and building specific smart projects to meet the objective needs of the city is the basic principle for completing the construction. The existing city characteristic analysis models analyze different cities by using population, economic scale, traffic conditions, industrial strength, service industry strength, and innovation capacity as analysis factors. Among them, the population factor is calculated using the number of city populations; the economic scale is calculated using the regional gross domestic product; the traffic conditions are calculated using the turnover of goods or the turnover of tourists; the authorization calculation of industrial strength is calculated using the added value of the industry or the added value of the secondary industry. The analysis of city characteristics is the basis for the construction of a smart city model, but this analysis model does not take into account factors such as the city environment, government services, infrastructure, etc. The resulting analysis results may not meet the needs of actual work and there are certain limitations in a city which can be regarded as an organization, and a smart city is the result of the development of city informatization to a certain stage. To this end, the theoretical model applicable to the development of organizational informatization can theoretically also be used to build a smart city development path and city informatization. By analyzing the stage of each city's informatization, combined with the city's development goals and needs, it can better build the development path of smart city [13].

\section{Strategic Management of Smart City Based on Digital Economy}

4.1. Integrated Management of Sharing Scheduling City Resources. Market demand is the driving force behind the sustainable development of smart city. The focus of smart city construction is to give play to the role of the market in allocating resources, to create various personalized smart applications that meet market needs through price, competition, and other factors, to foster a good state of emerging markets, and to promote new growth in the smart city economy. Technological innovation and the development of strategic emerging industries are important foundations for the construction of smart city. First of all, the construction of public service platforms must be strengthened in technology research and development, application testing, evaluation, and inspection, and the technological innovation environment also needs to be improved (Figure 3). The second is to promote the transformation of the dynamic mechanism of city development, improve the city industrial structure, and promote the emergence of new industrial forms with smart technological innovation. Finally, the key to strengthening technological research and development is to cultivate professional talents and make them the intellectual resources for smart city development. The construction process needs to make a reasonable top-level design based on the nature, characteristics, and functions of the city and establish a long- 
TABLE 1: Rating system of smart city resource scheduling based on digital economy.

\begin{tabular}{|c|c|c|c|c|}
\hline Rating index system & $\begin{array}{c}\text { Smart foundation } \\
\text { operation }\end{array}$ & $\begin{array}{l}\text { Smart management } \\
\text { services }\end{array}$ & $\begin{array}{l}\text { Smart economy } \\
\text { humanity }\end{array}$ & Smarti ntegrated support \\
\hline Network connection level & 0.836 & 0.623 & 0.735 & 0.838 \\
\hline $\begin{array}{l}\text { Service interaction } \\
\text { platform }\end{array}$ & 0.783 & 0.416 & 0.511 & 0.769 \\
\hline Technology infrastructure & 0.804 & 0.327 & 0.850 & 0.642 \\
\hline City marking technology & 0.735 & 0.020 & 0.255 & 0.523 \\
\hline Operation management & 0.843 & 0.134 & 0.146 & 0.114 \\
\hline Personal consumption & 0.632 & 0.463 & 0.347 & 0.745 \\
\hline Society environment & 0.957 & 0.032 & 0.966 & 0.758 \\
\hline Culture environment & 0.362 & 0.217 & 0.675 & 0.483 \\
\hline Government policy & 0.235 & 0.948 & 0.107 & 0.956 \\
\hline Business application & 0.145 & 0.566 & 0.524 & 0.046 \\
\hline Business environment & 0.521 & 0.211 & 0.122 & 0.919 \\
\hline Analysis function & 0.165 & 0.925 & 0.694 & 0.544 \\
\hline Cloud management & 0.238 & 0.866 & 0.437 & 0.312 \\
\hline Monitoring warning & 0.366 & 0.618 & 0.724 & 0.073 \\
\hline Resource scheduling & 0.122 & 0.345 & 0.159 & 0.479 \\
\hline Standard system & 0.434 & 0.584 & 0.335 & 0.249 \\
\hline Information security & 0.593 & 0.483 & 0.135 & 0.185 \\
\hline Decision support & 0.453 & 0.293 & 0.674 & 0.835 \\
\hline Solution logic & 0.065 & 0.484 & 0.484 & 0.686 \\
\hline Strategy guidance & 0.968 & 0.204 & 0.597 & 0.548 \\
\hline
\end{tabular}

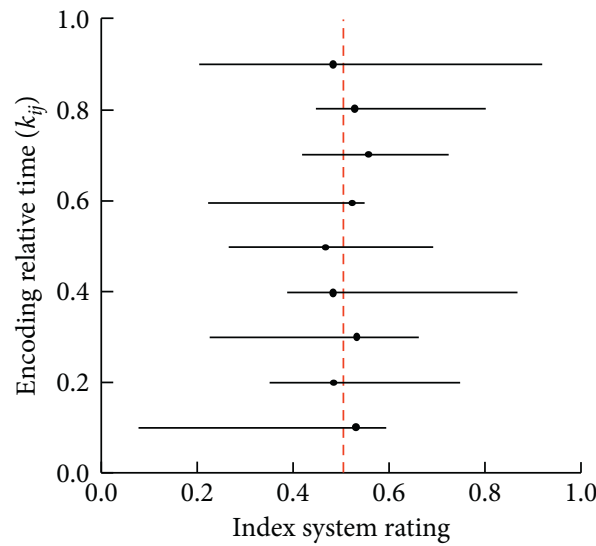

(a)

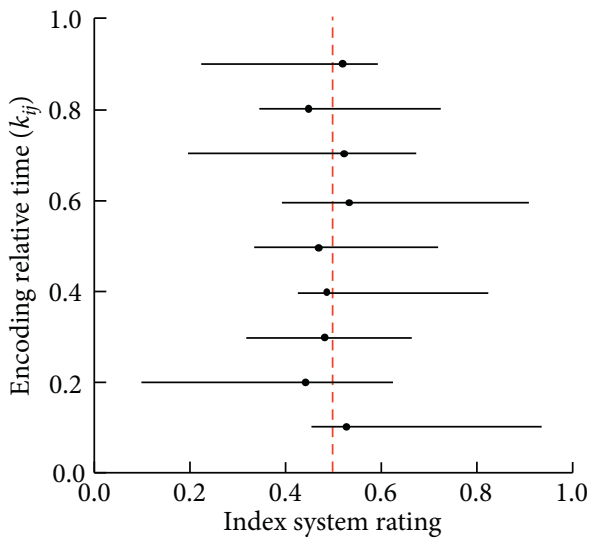

(b)

Figure 2: Relationship between encoding relative time and index system rating in the (a) resource scheduling and (b) strategic management of smart city based on digital economy.

term institutional guarantee. At present, the construction of smart city is mainly to give full play to advantages or solve shortcomings. Depending on the focus of city construction, the common goal is to identify obstacles to their own development; in some cities, the focus of construction is to give play to their advantages and promote economic development in a targeted manner.

A smart city is a complex large-scale system project, and its security problems will manifest in the system's information-awareness layer, access and transmission layer, application layer and terminal layer, intelligent processing, and collaborative platform layer. If sudden safety problems are encountered, the impact will involve the entire city, which may lead to factory shutdowns, store shutdowns, electrical interruptions, traffic paralysis, water cuts, etc., which will have extremely serious consequences [14]. Therefore, they should be practically paid more attention to and dealt with and its heterogeneous interconnection, multihop, and distribution characteristics will make it more difficult to integrate and integrate its security system due to the use of a heterogeneous system platform. The different methods of equipment, storage, processing, and detection make information security, information transmission, and processing, which are also difficult to unify; the equipment is often in unattended, adaptive management, self-disconnection, and self-connecting states, which also increases the difficulty of designing and implementing security systems. Specifically, the integrity, authenticity, confidentiality, 


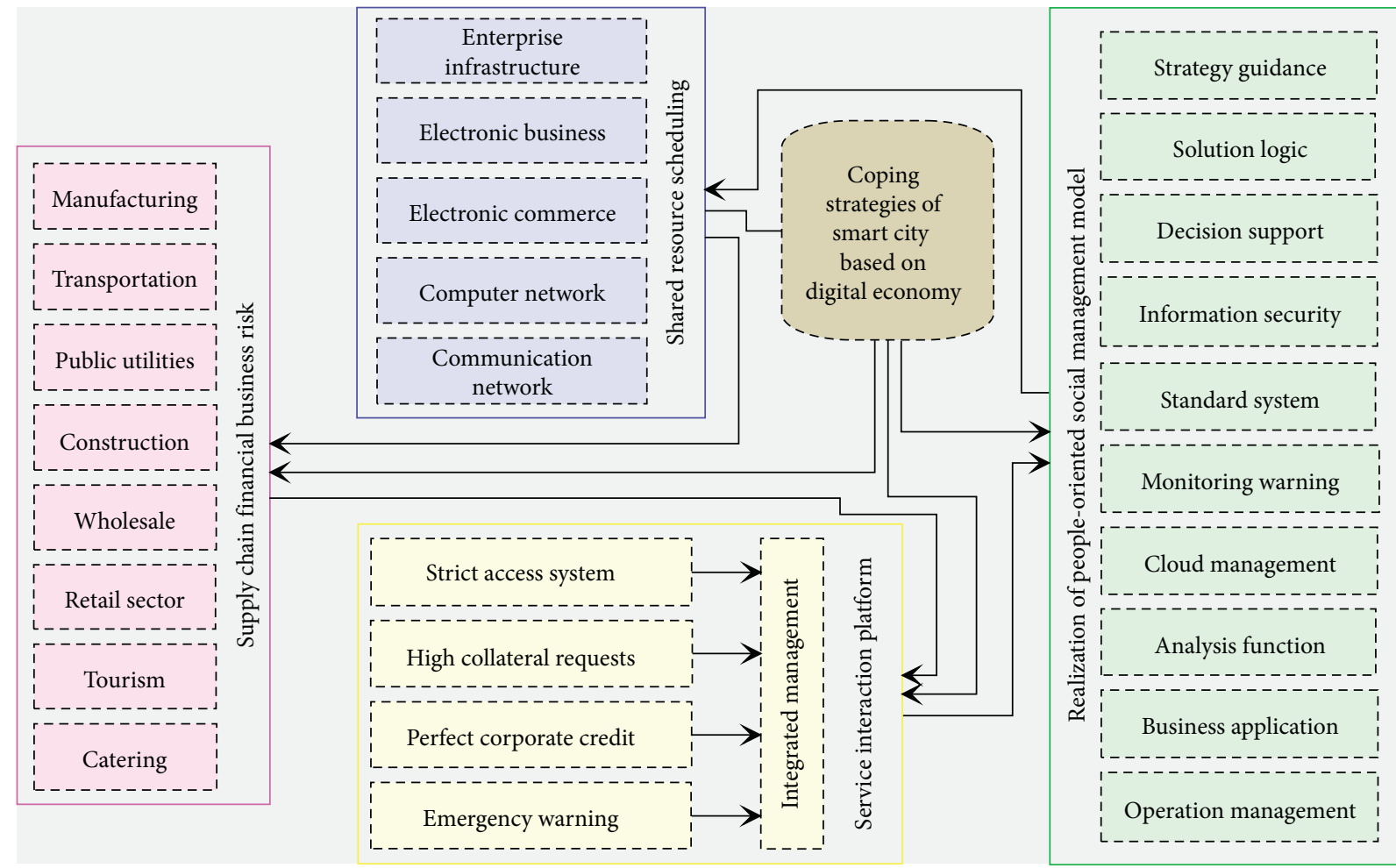

FIGURE 3: Integrated and people-oriented strategic management of smart city based on digital economy.

availability, fault tolerance, and self-organizing ability of massive data collection should be guaranteed for the ubiquitous network sensing layer with self-organizing characteristics. For this reason, special attention should be paid to solving physical-level attacks for obtaining stored passwords and data, and to handle encryption, decryption, identity authentication and signature, and key security issues.

In the future, the data of smart city will be aggregated and dispersed and convergence means that public information platforms gather, extract, and analyze various heterogeneous and heterogeneous data. The dispersion means that data from vertical industries or different government agencies and enterprises will be separated due to their natural nature which may be distributed across different private and public cloud data centers. According to the city's budget and planning, the solution can be based on three key platforms: infrastructure platform, centralized management, and flexible scheduling of network resources, allowing more embedded infrastructure. The intelligent processing platforms can consolidate and improve service delivery, intelligent innovation platform, and modular service channels, including user self-service, social networking sites, application incubation, and service support call centers by identifying service priorities, expanding [15]. The key business capabilities of smart city should move closer to the trends of cloud computing and mobile and social networks. As cloud computing deployments and the number of users increase, vendors will inevitably transition to service providers or choose the right partners. The social networks can not only capture and analyze user data in real time, but also provide important feedback mechanisms that the public can use socially software or feedback to the government and manufacturers on services and suggestions at any time through social media, promote the improvement of service quality, and create more business opportunities.

\subsection{Realization of People-Oriented Social Management Model.} The smart city is supported by spatiotemporal information and relies on modern information technologies such as the Internet of Things and cloud computing to materialize human knowledge into various activities such as city planning, design, construction, management, operation, and development under informative conditions. The industry sector proportion of digital economy in smart city construction is shown in Table 2. A smart city should include real-time information sensing devices like human senses, two-way transmission of information and instructions like human nervous systems, ubiquitous network systems, and cloud computing service centers like human brains, and response and human behavior organs. A smart city cannot be separated from the support of the geospatial framework [16]. The geospatial framework is the responsibility of the geographic information department of mapping, and it is also the infrastructure for city informatization. In the digital city phase, the main content of the geospatial framework is presented as a basic geographic information database and a public geographic information platform. With the development of the Internet of Things and cloud computing technologies, the basic geographic information database has become a spatiotemporal information database, and the 
TABLE 2: Industry sector proportions of digital economy in smart city construction.

\begin{tabular}{lcccc}
\hline Industry sector & Infrastructure of enterprises & Electronic business & Electronic commerce & Computer network \\
\hline Manufacturing & 0.738 & 0.379 & 0.584 & 0.129 \\
Transportation & 0.569 & 0.448 & 0.172 & 0.245 \\
Public utilities & 0.642 & 0.285 & 0.481 & 0.176 \\
Construction & 0.723 & 0.316 & 0.236 & 0.441 \\
Wholesale & 0.614 & 0.408 & 0.141 & 0.213 \\
Retail & 0.358 & 0.215 & 0.563 & 0.277 \\
Tourism & 0.657 & 0.226 & 0.370 & 0.545 \\
Catering & 0.365 & 0.466 & 0.421 & 0.428 \\
Information & 0.812 & 0.354 & 0.304 & 0.397 \\
Communication & 0.764 & 0.265 & 0.143 \\
\hline
\end{tabular}

public geographic information platform has become a spatiotemporal information cloud platform. In the smart city stage, the geospatial framework has spatiotemporal characteristics and has evolved into a spatiotemporal information framework. The core content includes a spatiotemporal information database and a spatiotemporal information cloud platform.

For information, it is mainly to use language, characters, numbers, symbols, and other media to form special symbols to represent the content and characteristics of objective things; for data, it is mainly the carrier of information. In building a smart city, different methods need to be used to collect information, organize information, and analyze information. There are many types of information, such as natural information, social information, humanistic information, geographic information, etc. The transformation of digital cities into smart city is an inevitable requirement for the development of digital cities and an important way for cities to realize informatization (Figure 4). In the construction of digital cities, a variety of information has been gathered to ensure the normal construction, planning, management, and operation of the city. When building a smart city, the results of digital cities should be fully used to apply the information and data of digital cities. In the construction of smart city, this will promote the construction of smart cities. The construction of a smart city is to better and more scientifically manage the city, so as to improve people's living standards and let people feel the results brought by the smart city. Therefore, when building a smart city, the management decision-making platform should be optimized and improved on the basis of a digital city, so as to promote the application of smart city in transportation, medical treatment, and public safety spatial geographic information [17].

The smart city will multiply the city economy to some extent. Firstly, the research and development, manufacturing, and application of the Internet of Things, the Internet, supercomputers, and data processing and computing technologies and these high-tech capital-intensive industries will become new engines of economic growth and industrial upgrading and will generate a wide range, large markets, smart industrial chain, and industrial clusters with long chains and multiple connections. Secondly, while promoting the upgrading of city operating systems, a smart city will also make the wealth creation activities based on city operating systems more convenient and efficient. A smart city is a product of the combination of a virtual economy and a real economy, and it will bring profound changes to city development. The construction of a smart city, through the widespread application of smart technologies, can increase the contribution of knowledge, technology, and information resources to economic growth. It can not only save material resources, reduce resource and energy consumption, reduce environmental pollution, and improve resource allocation efficiency, but also promote the transformation of economic development from labor-intensive and capital-intensive to knowledge-intensive and technology-intensive and accelerate the optimization and adjustment of economic structure. As a result of transformation and upgrading, some intelligent industrial chain and industrial groups with a wide range, large market, long chain, and many connected have been born; economic development is more intelligent, which in turn enhances the city's innovation and competitiveness.

\section{Discussion}

5.1. Multifactor Analysis of Economic Growth in the Context of Smart City Construction. The foundation of a smart city is a digital city, which can innovate in a measurable and visualized management and operation form of the digital city and create a networked comprehensive city decision-making and city management platform in the city's data and information infrastructure. The wireless network and the data network constitute a wireless sensor network, which is datacentric and designed for a certain requirement. The wireless sensor network refers to the realization of real-time monitoring of each node based on the wireless network for a certain characteristic application and can collect the information of the detection object and the environment information in the network and then process it to pass it to the user in more detail and comprehensive information (Figure 5). The network must have the ability to autonomously organize and reconfigure; when a node in the layout fails due to changes in the environment, the network topology changes over time. Therefore, the network is required to have the function of maintaining dynamic routing. Failures can occur due to node failure. Intelligent transportation systems can improve the efficiency of transportation systems, realize intelligent, networked, information and integrated transportation systems, and intelligently collect traffic flow, information, noise, and traffic accidents. The 


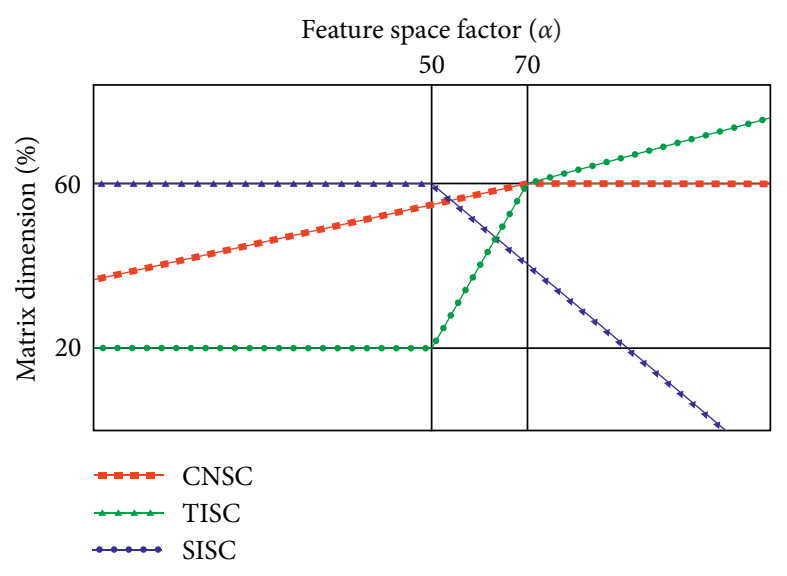

(a)

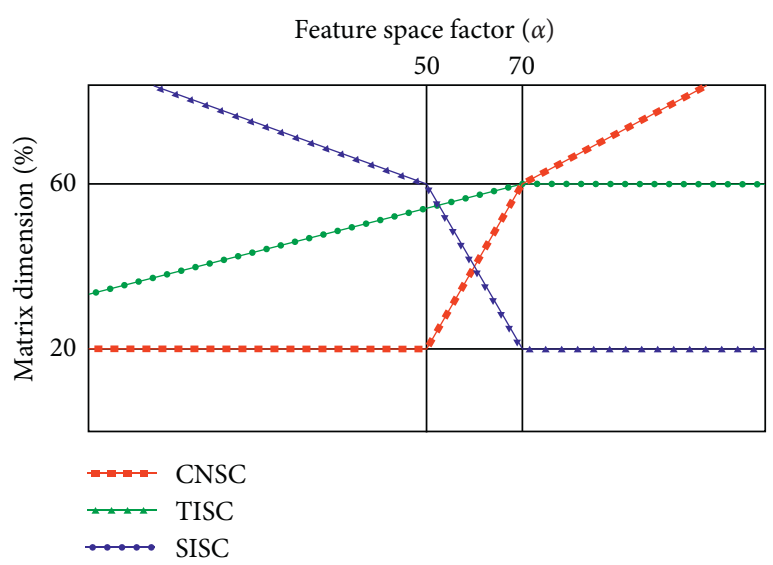

(b)

Figure 4: Relationship between matrix dimension and feature space factor of smart city's construction model based on digital economy. CNSC, network connection of smart city; SISC, service interaction of smart city; TISC, technology infrastructure of smart city.

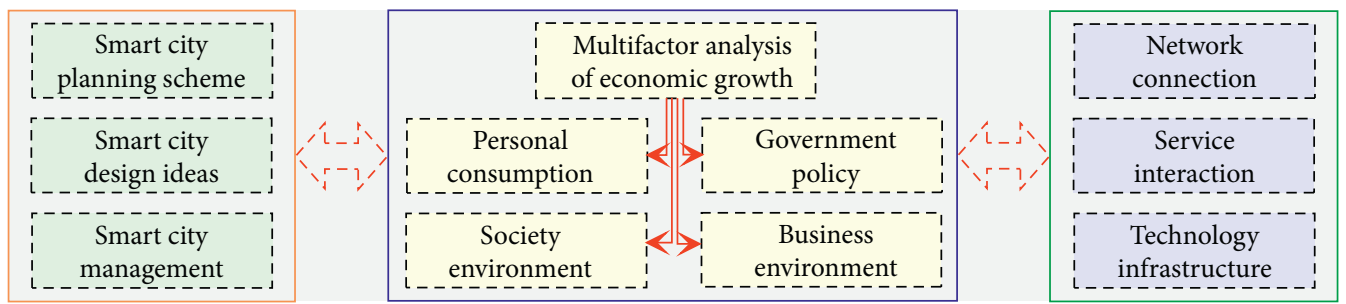

FIGURE 5: Multifactor analysis of economic growth in the context of smart city construction.

environments can communicate with each other to improve the safety and economy of the transportation system.

The intelligent applications will facilitate the management of the city and the life of citizens, while also collecting extensive user information, which will become the basis for planning, resource deployment, research, and analysis by government and other decision-making agencies. In the field of a smart city, data has a very important status, including geospatial data, industry data, census data, sensor monitoring data, etc., which are the basis of smart city construction [18]. The market demand is analyzed from infrastructure of enterprises, electronic business, electronic commerce, and computer network. The technological innovation environment of market demand must be first optimized and the public integrated process of the service platform then should be improved to guide the whole society to actively innovate and start businesses. The proposal of the integration of cities and industries is an inevitable requirement for responding to the transformation of industrial functions and the improvement of comprehensive city functions. It also reflects the trend of city planning from functionalism to humanism. From the focus on functional zoning and industrial structure, the focus is on integration and development and also is on people's initiative and the transformation of innovation and development. The smart cities emphasize the high degree of integration of industrialization and informationization and rely on the development of highly developed information infrastructure to create conditions for the extensive interconnection and interconnection of city big data. The digital economy will build a smart park into a comprehensive high-tech park that integrates technology research and development, public platforms, demonstrations, system integration, and consulting services. With the help of geographic information technology, the citizen information terminal integrates city management information and establishes a precise, efficient, comprehensive, and visual city management model.

The smart city construction is a systematic project that requires a large amount of funds to support it. Therefore, it is necessary to broaden the financing channels, especially to promote the participation of social capital. The government should accurately convey the value information of smart city construction and, for social capital investors, then accelerate the financing of smart city construction through energysaving bonds, green bonds, etc. (Figure 6). This is a feasible strategy to promote the development and development of smart city. Information and communication are two key technologies in the construction of smart city, so they cannot be measured according to a specific technical term. Instead, they should be judged based on value functions. For example, in the process of clarifying water standards, network speed and coverage of the scope, penetration rate, timeline, etc. are clearly defined so as to better meet the needs of functional parameters in the construction of smart city under clear technical standards to achieve convergence with the development of future cities [9]. In addition, the smart city construction is a systematic project, so during the construction process, a management system that can be used 


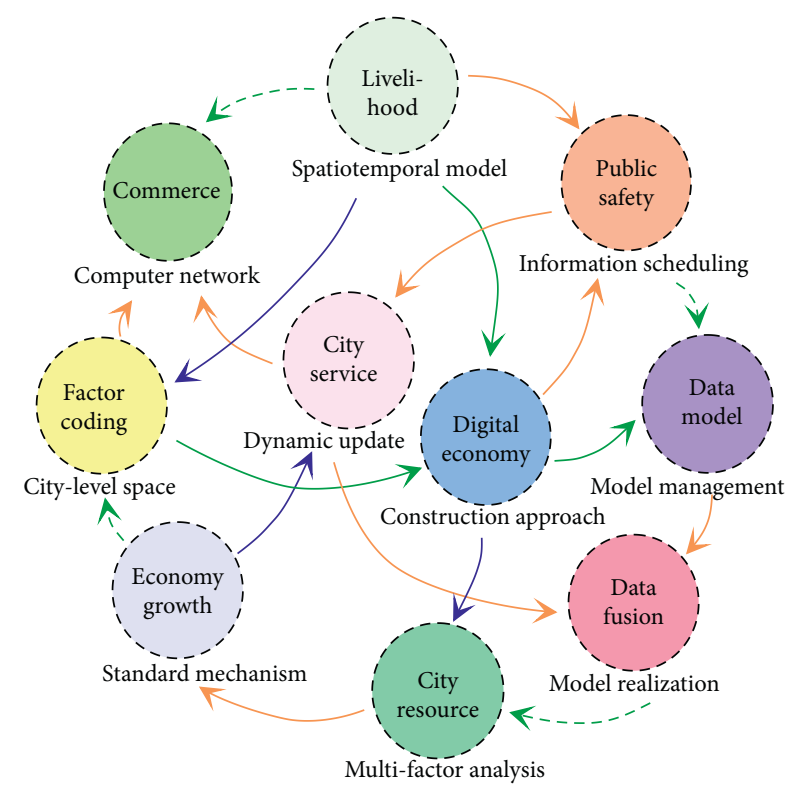

FIGURE 6: Realization of people-oriented social management model based on digital economy.

by decision-makers to judge success or failure should be established first, so as to continuously evaluate the plan progress, and it should also provide a certain early warning function, so as to ensure the steady progress of smart city construction.

\subsection{Standardization Construction Mechanism of Smart City.} The competition for smart city development includes competition for industries, markets, talents, and investment and development opportunities; and the development has the corresponding effect, and resources will quickly gather to the core. When a place is successful, it will close the possibility of neighboring cities to follow the same road and an area cannot form two centers with the same characteristics. The success of regional development strategies is often not entirely determined by their own wishes and the development strategies of surrounding cities will affect the implementation of established strategies. The behavior of other regions is unpredictable and these uncertainties make static city planning extremely risky. At present, the emergence of industrial development plans in cities will inevitably greatly reduce the success rate of the plans. Because city information industry development planning is the field with the highest isomorphism, localities generally lack ideas and innovations in planning software, service outsourcing, digital content industry, Internet industry, and Internet of Things industry. The generation of isomorphic planning is based solely on the results of digital analysis and the same trend data can only lead to the same recommendations. The information industry planning is a risk decision in the face of uncertainty (Figure 7). The engineering logic cannot give innovative power, which suggests that the regional industrial planning must be independent and take risks [19].
The information service providers in the middle of the industry chain mainly include various information technology companies and network operation providers. The information service providers include software and application development, information integration and transmission, large-scale data processing, and cloud computing. The network operation provider is mainly responsible for project investment, construction, and operation and then resells or leases it to the government to provide basic communication and broadband network operation functions. The operation and service providers are important links in the industrial chain and midstream smart city construction system integrators present a trend. They have begun to move from the field of smart applications to the top-level design of smart city and from small integration of some applications to large integration of smart city construction, trying to establish standards and seize the right to operate a smart city (Figure 8). The industrial chain for the construction of a smart city contains all the content for the development of a smart economy industry and becomes an operating platform to realize data monetization. The key to smart economy is the development and integration of the smart city construction industry chain and the key to the latter lies in the coordinated and innovative development of the industry. Through the penetration, crossover, and reorganization of information, technology, talents, funds, and other resources, the entire wisdom is reconstructed. The industrial chain of city construction and even the city system promotes the development of smart industries and forms a smart economy.

The smart cities are digitally networked, intelligent, interactive, and synergistic at the technical level and they are especially demanding for the level of interconnection and interoperability of various city systems, at the social, economic, cultural, and educational levels. This emphasizes people-centered sustainable innovation and focuses on the collaborative sharing of a knowledge-based society, which involves a wide range of aspects, which determines that the construction of a smart city urgently requires the comprehensive use of various information technologies and products, as well as the innovation of business operations and public service models [20]. Therefore, the best order function of standard formulation can be used to solve problems such as data fusion and sharing in the construction of smart city, and the use and reuse of standardized activities to build, innovate, and promote related models of smart city construction. The mechanism between the two relationships can be developed from the following aspects and the construction of a smart city is a new thing, and it is necessary to constantly explore and accumulate experience in the construction. Among them, the promotion of replication and demonstration pilots is an effective way. In this process, standardization can transform the valuable and fully available results of the pilot into standard specifications in a timely manner, form a standardized working model for smart city construction, and promote the demonstration pilots to be carried out in a wider and deeper field. 


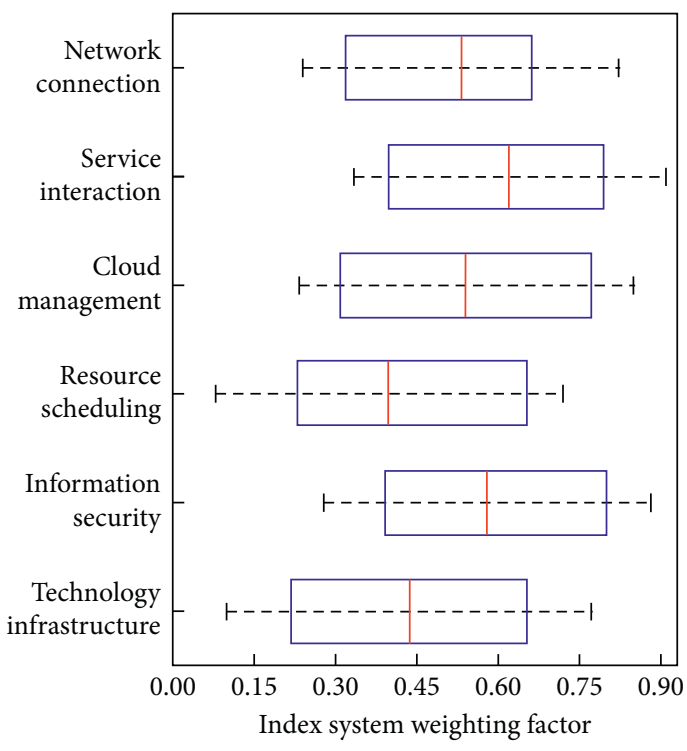

(a)

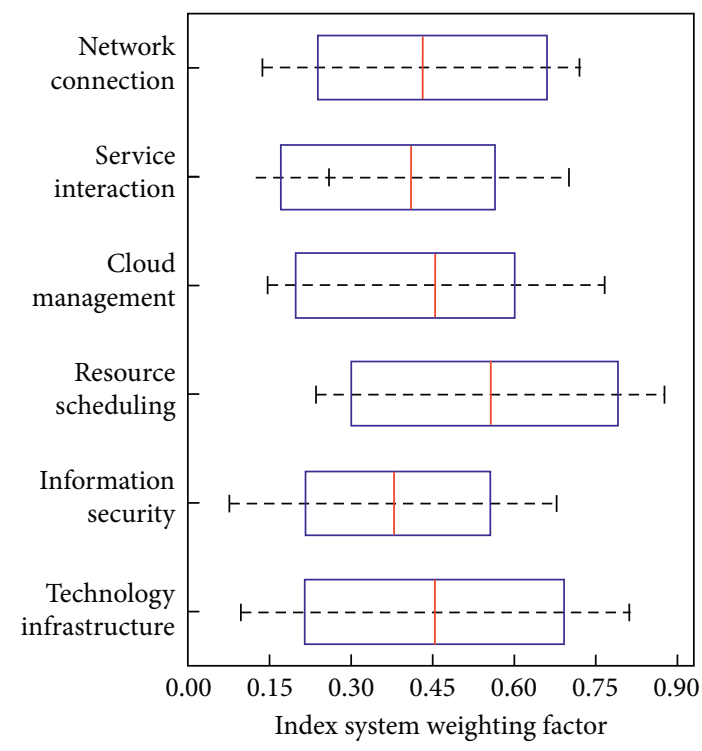

(b)

FIGURE 7: Index systems weighting factors of different indicators in the resource scheduling (a) and strategic management (b) of smart city based on digital economy.

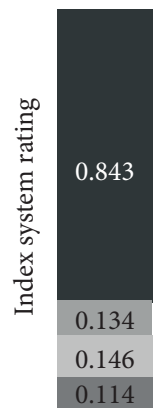

Operation management

SFO

SMS

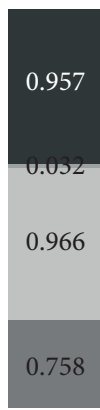

Society environment

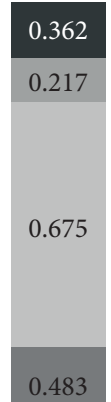

Culture environment ndex system

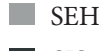

SIS

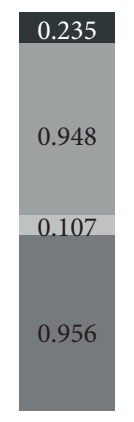

Government policy

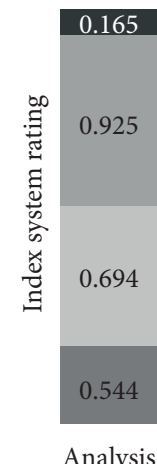

function

SFO

SMS

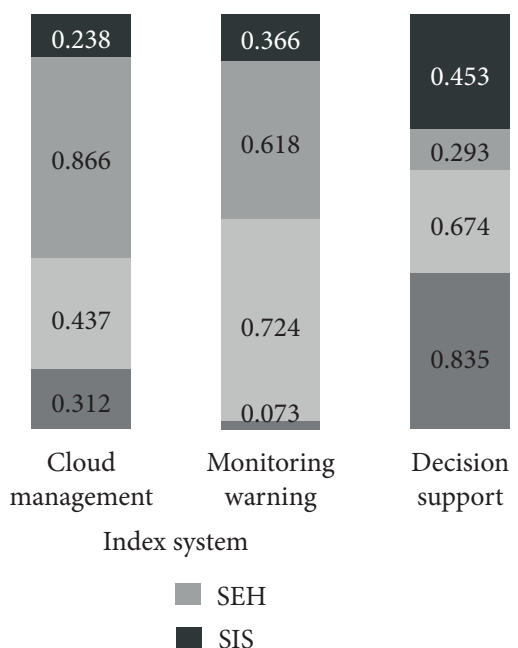

(b)

(a)

FIGURE 8: Index system rating of the resource scheduling (a) and strategic management (b) of smart city based on digital economy. SFO, smart foundation operation; SMS, smart management services; SHE, smart economy and humanity; SIS, smart integrated support.

\section{Conclusions}

This paper formulated resource scheduling strategies for a smart city based on digital economy, explored the dynamic fusion, storage, and update of a smart city's multisource heterogeneous data, conducted the information display and analysis of multilevel smart city, proposed strategic management approaches for a smart city based on digital economy, analyzed the integrated implementation model of shared resource scheduling and people-oriented social management, and discussed the economic growth factors and standardization mechanism of a smart city under the background of digital economy. In the digital economy, digital networks and communication technology facilities provide a global platform for individuals and organizations around the world to achieve mutual communication, communication, and cooperation. In the digital economy, transactions usually have the characteristics of digitization, virtualization, concealment, and electronic payment, which make it difficult to judge the consumption of trading venues and provide goods and services. The focus of smart city construction is to give play to the role of the market in allocating resources, to create various personalized smart applications that meet market needs through price, competition, and other factors, to foster a good state of emerging markets, and to promote new growth in the smart city 
economy. The core of a smart city is a smarter way to change the way governments, communities, or companies and people interact with each other through a new generation of information technology to improve the clarity, efficiency, flexibility, and response speed of interactions and the characteristics are perception, interconnection, and intelligence. The results of this study provide a reference for further researches on the resource scheduling and strategic management of a smart city under the background of digital economy.

\section{Data Availability}

The data used to support the findings of this study are available from the corresponding author upon request.

\section{Conflicts of Interest}

The authors declare that they have no conflicts of interest.

\section{Acknowledgments}

This work was supported by the project of the National Social Science Fund (No. 17BGL030) and Youth Scientific Research and Innovation Fund Project of Henan University of Animal Husbandry and Economy (No. XKYCXJJ2017006).

\section{References}

[1] F. Li, A. Nucciarelli, S. Roden, and G. Graham, "How smart cities transform operations models: a new research agenda for operations management in the digital economy," Production Planning \& Control, vol. 27, no. 6, pp. 514-528, 2016.

[2] O. O. Komarevtseva, "Smart city technologies: new barriers to investment or a method for solving the economic problems of municipalities?" R-economy, vol. 3, no. 1, pp. 32-39, 2017.

[3] A. Glasmeier and S. Christopherson, "Thinking about smart cities," Cambridge Journal of Regions, Economy and Society, vol. 8, no. 1, pp. 3-12, 2015.

[4] T. Shelton, M. Zook, and A. Wiig, "The "actually existing smart city"' Cambridge Journal of Regions, Economy and Society, vol. 8, no. 1, pp. 13-25, 2015.

[5] A. Wiig, "The empty rhetoric of the smart city: from digital inclusion to economic promotion in Philadelphia," Urban Geography, vol. 37, no. 4, pp. 535-553, 2016.

[6] R. Kitchin, "Making sense of smart cities: addressing present shortcomings," Cambridge Journal of Regions, Economy and Society, vol. 8, no. 1, pp. 131-136, 2015.

[7] R. Khatoun and S. Zeadally, "Cybersecurity and privacy solutions in smart cities," Institute of Electrical and Electronics Engineers Communications Magazine, vol. 55, no. 3, pp. 51-59, 2017.

[8] G. Ferrara, "Smart city: a geographical perspective," Romanian Review on Political Geography, vol. 8, no. 2, pp. 43-48, 2016.

[9] R. G. Hollands, "Critical interventions into the corporate smart city," Cambridge Journal of Regions, Economy and Society, vol. 8, no. 1, pp. 61-77, 2015.

[10] L. Anthopoulos, "Smart utopia VS smart reality: learning by experience from 10 smart city cases," Cities, vol. 63, pp. 128-148, 2017.

[11] V. Kupriyanovsky, A. Ishumuratov, D. Namiot, D. Yartsev, N. Utkin, and D. Nikolaev, "Digital economy and the Internet of things-negotiating data silo," International Journal of Open Information Technologies, vol. 4, no. 8, pp. 36-42, 2016.

[12] J. Sun, J. Yan, and K. Z. Zhang, "Blockchain-based sharing services: what blockchain technology can contribute to smart cities," Financial Innovation, vol. 2, no. 1, pp. 1-9, 2016.

[13] P. Cardullo and R. Kitchin, "Being a "citizen" in the smart city: up and down the scaffold of smart citizen participation in Dublin, Ireland," GeoJournal, vol. 84, no. 1, pp. 1-13, 2019.

[14] C. C. Snow, D. D. Håkonsson, and B. Obel, "A smart city is a collaborative community," California Management Review, vol. 59, no. 1, pp. 92-108, 2016.

[15] D. Namiot, V. Kupriyanovsky, A. Samorodov, O. Karasev, D. Zamolodchikov, and N. Fedorova, "Smart Cities and education in digital economy," International Journal of Open Information Technologies, vol. 5, no. 3, pp. 56-71, 2017.

[16] V. Albino, U. Berardi, and R. M. Dangelico, "Smart cities: definitions, dimensions, performance, and initiatives," Journal of Urban Technology, vol. 22, no. 1, pp. 3-21, 2015.

[17] S. P. Caird and S. H. Hallett, "Towards evaluation design for smart city development," Journal of Urban Design, vol. 24, no. 2, pp. 188-209, 2019.

[18] K. Kourtit, P. Nijkamp, and J. Steenbruggen, "The significance of digital data systems for smart city policy," Socio-Economic Planning Sciences, vol. 58, pp. 13-21, 2017.

[19] N. Komninos, C. Bratsas, C. Kakderi, and P. Tsarchopoulos, "Smart city ontologies: improving the effectiveness of smart city applications," Journal of Smart Cities, vol. 1, no. 1, pp. 31-46, 2019.

[20] T. Yigitcanlar, M. Kamruzzaman, L. Buys et al., "Understanding "smart cities": intertwining development drivers with desired outcomes in a multidimensional framework," Cities, vol. 81, pp. 145-160, 2018. 